\title{
Hydrogen-Rich Gas Production by Cogasification of Coal and Biomass in an Intermittent Fluidized Bed
}

\author{
Li-Qun Wang and Zhao-Sheng Chen
}

School of Energy and Power Engineering, Jiangsu University, 301 Xuefu Road, Zhenjiang 212013, China

Correspondence should be addressed to Li-Qun Wang; zhaoshengchen2010@126.com

Received 3 July 2013; Accepted 2 August 2013

Academic Editors: A. Duta, A. Klimenko, A. Piacentino, and A. Sınağ

Copyright (C) 2013 L.-Q. Wang and Z.-S. Chen. This is an open access article distributed under the Creative Commons Attribution License, which permits unrestricted use, distribution, and reproduction in any medium, provided the original work is properly cited.

\begin{abstract}
This paper presents the experimental results of cogasification of coal and biomass in an intermittent fluidized bed reactor, aiming to investigate the influences of operation parameters such as gasification temperature ( $T$ ), steam to biomass mass ratio (SBMR), and biomass to coal mass ratio (BCMR) on hydrogen-rich $\left(\mathrm{H}_{2}\right.$-rich) gas production. The results show that $\mathrm{H}_{2}$-rich gas free of $\mathrm{N}_{2}$ dilution is produced and the $\mathrm{H}_{2}$ yield is in the range of $18.25 \sim 68.13 \mathrm{~g} / \mathrm{kg}$. The increases of T, SBMR, and BCMR are all favorable for promoting the $\mathrm{H}_{2}$ production. Higher temperature contributes to higher $\mathrm{CO}$ and $\mathrm{H}_{2}$ contents, as well as $\mathrm{H}_{2}$ yield. The BCMR has a weak influence on gas composition, but the yield and content of $\mathrm{H}_{2}$ increase with BCMR, reaching a peak at the BCMR of 4. The $\mathrm{H}_{2}$ content and yield in the product gas increase with SBMR, whilst the content of $\mathrm{CO}$ increases first and then decreases correspondingly. At a typical case, the relative linear sensitivity coefficients of $\mathrm{H}_{2}$ production efficiency to T, SBMR, and BCMR were calculated. The results reveal that the order of the influence of the operation parameters on $\mathrm{H}_{2}$ production efficiency is $\mathrm{T}>$ $\mathrm{SBMR}>\mathrm{BCMR}$.
\end{abstract}

\section{Introduction}

Hydrogen is likely to be an important energy carrier in the future [1]. However, the presence of hydrogen on Earth is limited to hydrogen-containing compounds and today, nearly $96 \%$ of hydrogen is produced from fossil fuels, which emit a large amount of carbon dioxide [2-4]. Conversely, biomass represents a clean and renewable energy resource with a carbon dioxide neutral effect on the environment. Therefore, biomass has been known as the most potential material for hydrogen production in the future [5].

Biomass gasification process has emerged as a clean and efficient way of producing hydrogen [6]. It is a well-known technology that can be classified depending on the reactor: fixed bed, moveable bed, fluidized bed, and so forth. The fluidized bed reactor has been widely used as the biomass gasifier to produce hydrogen due to its various advantages which include better temperature control, wide feedstock adaptability, good gas solids contact, and excellent heat and mass transfer characteristics. Different gases such as air [79], pure steam [10-12], and air-steam [13, 14] can be adopted as the gasifying mediums.
The addition of steam as a gasifying medium in gasification process makes it possible to obtain high-grade and nearly $\mathrm{N}_{2}$-free $\mathrm{H}_{2}$-rich gas [15]. However, there are a number of potential problems $[16,17]$ in biomass gasification with steam [16] as follows. (i) If the biomass reacts with both steam and air in one reactor, then nitrogen is present in product gases and is costly to remove $[13,14]$. (ii) If one tries to avoid this problem by using pure oxygen instead of air, then a source of pure oxygen would be needed, which is again a costly option [8]. (iii) It is possible to circumvent the separation "issues" by running "oxygenless" gasification and the combustion reactions in different locations, but then transferring heat from one location to the other is accompanied with heat losses [18-21]. In order to meet the heat needs of gasification, the combustion reactor requires higher temperature to compensate the heat losses [22].

In order to overcome the problems, a process concept which involves time-segregated hybridization of combustion/gasification reactions in one fluidized bed reactor is proposed. This process consists of two separate stages, that is, combustion and gasification, in a reactor. Specifically, the combustion stage is used for coal combustion fed with air. 
TABLE 1: Proximate and ultimate analyses of biomass and coal.

\begin{tabular}{lcccccccc}
\hline \multirow{2}{*}{ Samples } & \multicolumn{4}{c}{ Proximate analysis/wt.\% } & \multicolumn{3}{c}{ Ultimate analysis/wt.\% } \\
& Vol. & Mois. & FC & Ash & C & H & O \\
\hline Lean coal & 5.5 & 4.7 & 41.86 & 25.3 & 62.42 & 2.83 & 1.9 \\
Corn core & 67.8 & 5.6 & 9.9 & 5.9 & 47.53 & 4.9 & 37.75 \\
\hline
\end{tabular}

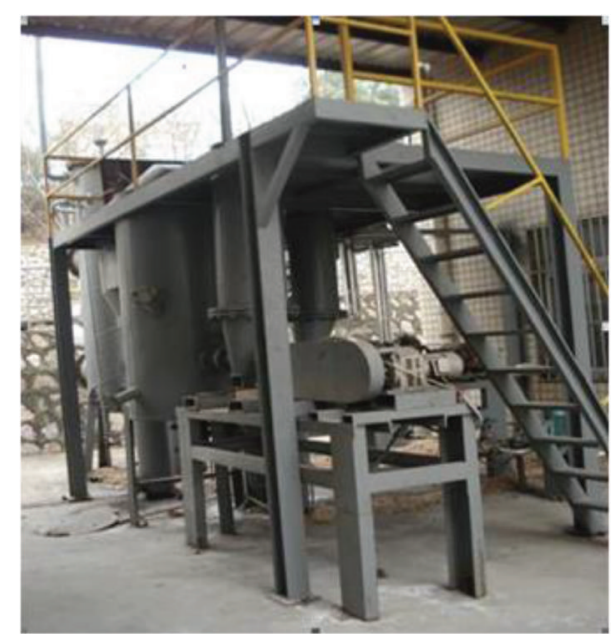

(a)

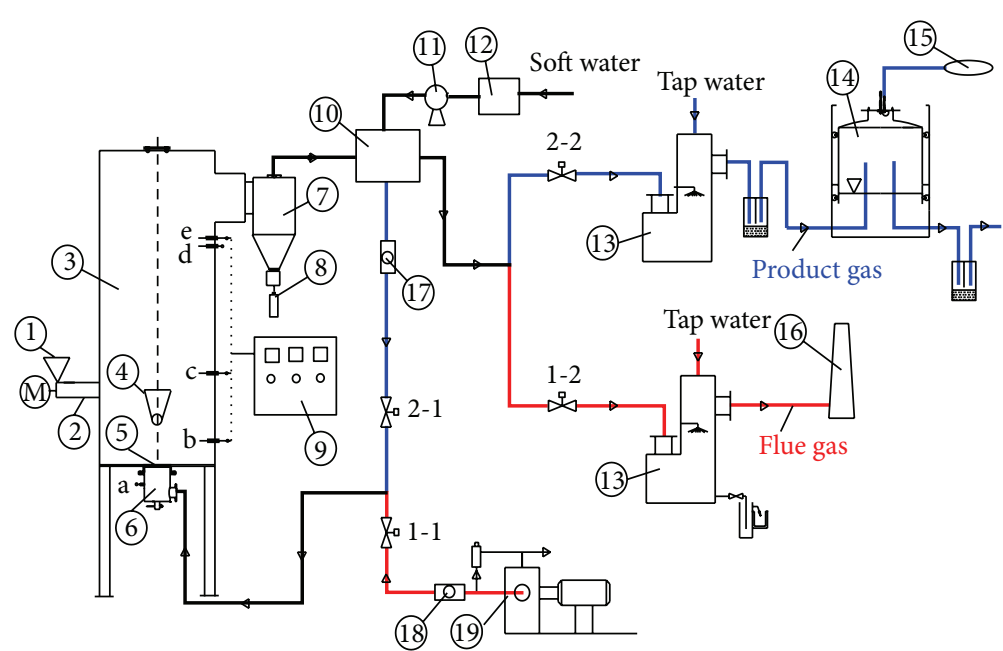

(b)

FiguRE 1: Cogasification of coal and biomass in an intermittent fluidized bed reactor. (a) Pilot plant, (b) schematic diagram: (1) biomass hopper; (2) screw feeder; (3) fluidized bed reactor; (4) coal feeder; (5) air distributor; (6) wind room; (7) high-temperature cyclone separator; (8) char collector; (9) PID temperature controller; (10) tube-type heat exchanger; (11) soft water pump; (12) soft water tank; (13) wet scrubber; (14) bell-type gas holder; (15) product gas collection bag; (16) chimney; (17) steam flow meter; (18) air flow meter; (19) roots blower, (b), (c) and (e): k-type thermocouple, (a) and (d): pressure taps; 1-1: air control valve (solenoid valve); 1-2: flue control valve (pneumatic valve); 2-1: steam control valve (solenoid valve); 2-2: gas control valve (pneumatic valve).

The biomass and pure steam are added in the gasification stage to serve as the gasification raw material during gasification. Direct contact between the combustion and gasification stages is avoided. This gasification technology operates in the same reactor; thus all the energy of coal combustion can be supplied in to the gasification stage, which proves to be better for tar cracking, and also can effectively prevent sintering of the raw materials in gasification process.

The objective of this study was to investigate the influences of $\mathrm{T}, \mathrm{SBMR}$, and $\mathrm{BCMR}$ on $\mathrm{H}_{2}$-rich gas production by cogasification of coal and biomass in an intermittent fluidized bed. Additionally, a sensitivity study was employed in order to provide a comparable measure of the influence of T, SBMR, and BCMR on $\mathrm{H}_{2}$ production efficiency.

\section{Experimental Part}

2.1. Raw Materials. In this study, corn core and lean coal obtained from Jiangsu Province, China, were employed as biomass and coal feedstock, respectively. The mean diameter of the biomass particles is $5 \mathrm{~mm}$, whereas that of the coal particles is $3 \mathrm{~mm}$. The proximate and ultimate analyses of the raw materials are reported in Table 1.

2.2. Facilities. The experimental system, whose schematic diagram is illustrated in Figure 1, consists of five main parts: (a) a fluidized bed reactor, (b) a temperature control section, (c) two feeding sections, (d) air and steam supplying sections, and (e) gas purifying, sampling, and metering sections. The fluidized bed reactor is a cylindrical, stainless steel shell with a supporting structure. The total height of the fluidized bed is $2000 \mathrm{~mm}$ and the inner diameter (id) is $300 \mathrm{~mm}$. Two pressure taps are mounted at the center of wind room and at the height of $1006 \mathrm{~mm}$ above the air distributor to monitor the pressure drop of the fluidized bed reactor. The bed temperatures at three different points along the height of 160,600 , and $1056 \mathrm{~mm}$ above the distributor are measured by K-type thermocouples with a diameter of $18 \mathrm{~mm}$. At the bottom of the fluidized bed reactor, an air distributor is installed for better air distribution. The distributor is $16 \mathrm{~mm}$ in thickness with 126 holes (id $=2 \mathrm{~mm}$ ) perforated uniformly on it. The coal and biomass are fed separately to the fluidized bed reactor by two different screw feeders. The feeding point is at $480 \mathrm{~mm}$ above the air distributor. The feeder pipes have external water-cooling heat exchanger to avoid raw materials pyrolysis before they enter the fluidized bed reactor. Air is introduced into the fluidized bed reactor below the distributor, as an oxidizing medium for coal combustion; in combustion stage, it is provided by a roots blower. The steam of $300^{\circ} \mathrm{C}$ is used as the gasification medium and also introduced from the bottom but in gasification stage, it is provided by a steam generator, and its mass flow rate 
is measured by a steam flow meter. The solid particulates (ash, dust, and char) from the high-temperature hot gas are separated by the high-temperature cyclone separator and collected at the bottom. The high-temperature hot gas is cooled to about $200^{\circ} \mathrm{C}$ by a water-cooled shell and tube-type heat exchanger. The gas then passed through a wet scrubber to condense organic vapors (tar) and further cool gas with tap water. Finally, the purified gas is introduced into the bell-type gas holder to storage.

2.3. Procedures. The technology divides the production process into combustion and gasification stages in the same reactor. Through two pairs of control valves (see Figure 1), namely, $1-1$ and 1-2 valves and 2-1 and 2-2 valves, two working stages are formed. During combustion stage, the first pair of valves is opened. Coal and air are added to the reactor when coal is combusted in fluid state, and the reactor temperature (or bed temperature) rapidly increases. When the bed temperature rises to the desired temperature and remains steady, the combustion stage ends, the air and coal supply ceases, and the first pair of valves is closed. Meanwhile the second pair of valves is successively opened. Biomass and steam are introduced to the reactor, thus inducing the high-temperature materials to undergo pyrolysis gasification reaction with pure steam in a fluid state. This produces $\mathrm{H}_{2}$-rich gas. Given that the reaction is of an intensive endothermic nature, the bed temperature rapidly declines. When the bed temperature decreases to the predetermined value, the gasification stage ends, the biomass and steam supply ceases, and the second pair of valves is closed. The control valves then return again to the combustion stage. This cycle is then repeated.

Both stages occur by controlling the two pairs of control valves dominated by the preprogrammed temperatures.

In gasification stage, the sample of the product gas was collected from the bell-type gas holder with gas bag and analyzed for major components $\left(\mathrm{H}_{2}, \mathrm{CO}, \mathrm{CO}_{2}\right.$, and $\left.\mathrm{CH}_{4}\right)$ by gas chromatograph (GC-2010, Shimadzu International Trading (Shanghai) Co, Ltd, China).

\section{Results and Discussion}

3.1. Influences of Temperature. The reaction temperature is an important factor with regard to the final composition of the gases and products distribution [23]. The main reactions in coal and biomass cogasification are listed as follows [24]:

$$
\begin{aligned}
& \text { Oxidation : Coal + Air } \\
& \stackrel{\text { combustion }}{\longrightarrow} \text { Heat }+\mathrm{C}_{\text {coal }}+\mathrm{CO}+\mathrm{CO}_{2}+\mathrm{N}_{2}+\cdots
\end{aligned}
$$

Pyrolysis : Biomass + Heat (from R1)

$$
\begin{gathered}
\stackrel{\text { pyrolysis }}{\longrightarrow} \mathrm{C}_{\text {biomass }}+\text { Tar }+ \text { Gases } \\
\text { Water-gas : }\left(\mathrm{C}_{\text {coal }}+\mathrm{C}_{\text {biomass }}\right)+\mathrm{H}_{2} \mathrm{O} \Longleftrightarrow \mathrm{CO}+\mathrm{H}_{2}
\end{gathered}
$$

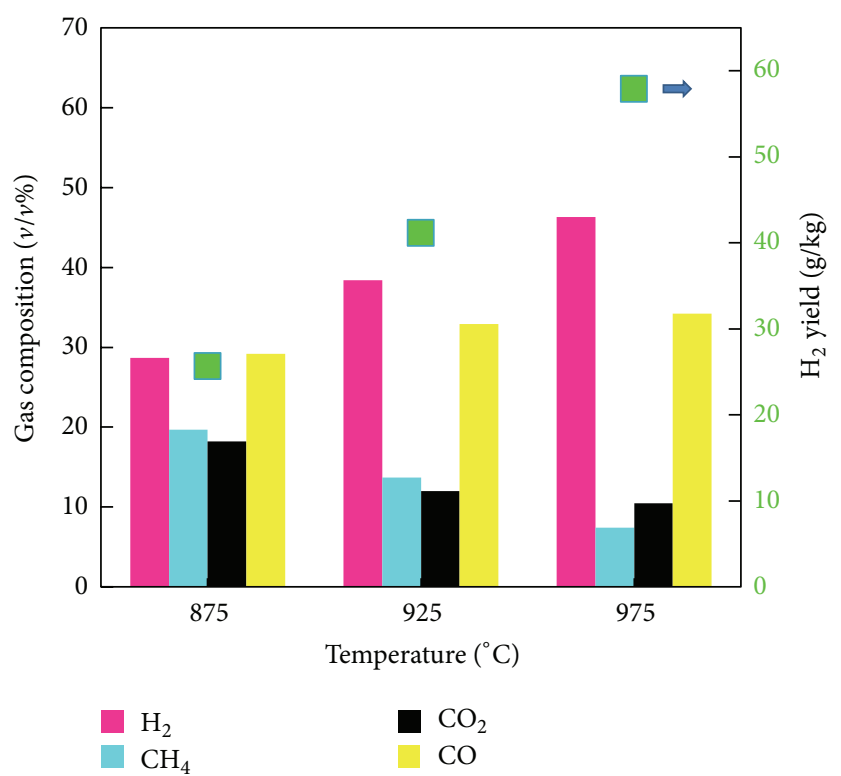

FIGURE 2: Influence of temperature on $\mathrm{H}_{2}$-rich gas production.

$$
\begin{aligned}
& \text { Boudouard : }\left(\mathrm{C}_{\text {coal }}+\mathrm{C}_{\text {biomass }}\right)+\mathrm{CO}_{2} \Longleftrightarrow 2 \mathrm{CO} \\
& \text { Water-gas shift : } \mathrm{CO}+\mathrm{H}_{2} \mathrm{O} \Longleftrightarrow \mathrm{CO}_{2}+\mathrm{H}_{2} \\
& \text { Steam reforming : } \mathrm{CH}_{4}+\mathrm{H}_{2} \mathrm{O} \Longleftrightarrow \mathrm{CO}+3 \mathrm{H}_{2} \\
& \text { Tar }+\mathrm{H}_{2} \mathrm{O} \stackrel{\text { decomposition }}{\longrightarrow} \text { Gases }\left(\mathrm{H}_{2}, \mathrm{CO}, \mathrm{CO}_{2}, \mathrm{CH}_{4}, \mathrm{C}_{\mathrm{n}} \mathrm{H}_{\mathrm{m}}\right)
\end{aligned}
$$

Methanation : $\left(\mathrm{C}_{\text {coal }}+\mathrm{C}_{\text {biomass }}\right)+2 \mathrm{H}_{2} \Longleftrightarrow \mathrm{CH}_{4}$

Figure 2 shows the influences of temperature on $\mathrm{H}_{2}$-rich gas production at SBMR of 1.3 and BCMR of 4 . It is found that the $\mathrm{H}_{2}$ content and yield in the product gas increased from $28.7 \%$ and $25.63 \mathrm{~g} / \mathrm{kg}$ at $875^{\circ} \mathrm{C}$ to $46.3 \%$ and $57.88 \mathrm{~g} / \mathrm{kg}$ at $975^{\circ} \mathrm{C}$, respectively. The main reason for the increase in $\mathrm{H}_{2}$ output is that the water gas reaction (R3) is promoted with increasing temperature.

Under steam coal and biomass cogasification conditions, the endothermic char gasification with water reaction (R3), the Boudouard char gasification with $\mathrm{CO}_{2}$ reaction (R4), and $\mathrm{CH}_{4}$ steam reforming reaction (R6) are accelerated with an increase in temperature resulting in an increase of $\mathrm{CO}$ and $\mathrm{H}_{2}$ and a decrease in $\mathrm{CH}_{4}$ and $\mathrm{CO}_{2}$. Moreover, $\mathrm{H}_{2}$ is greater than that of $\mathrm{CO}$, and the difference between the two gas contents increased with the rise of temperature. The presence of steam favors water gas shift reaction (R5) leading to an increase in $\mathrm{H}_{2}$ content and a decrease in $\mathrm{CO}$ concentration with the increase of temperature. Although (R6) reaction also releases $\mathrm{CO}_{2}$, the $\mathrm{CO}_{2}$ concentration decreases with the increase of temperature; this may be attributed to the (R4) reaction that consumes $\mathrm{CO}_{2}$ in return, resulting in an increase of $\mathrm{CO}$ concentration and a decrease in $\mathrm{CO}_{2}$ concentration with increased temperatures [25]. The experimental results seem to show that the (R6) reaction is less important for higher 


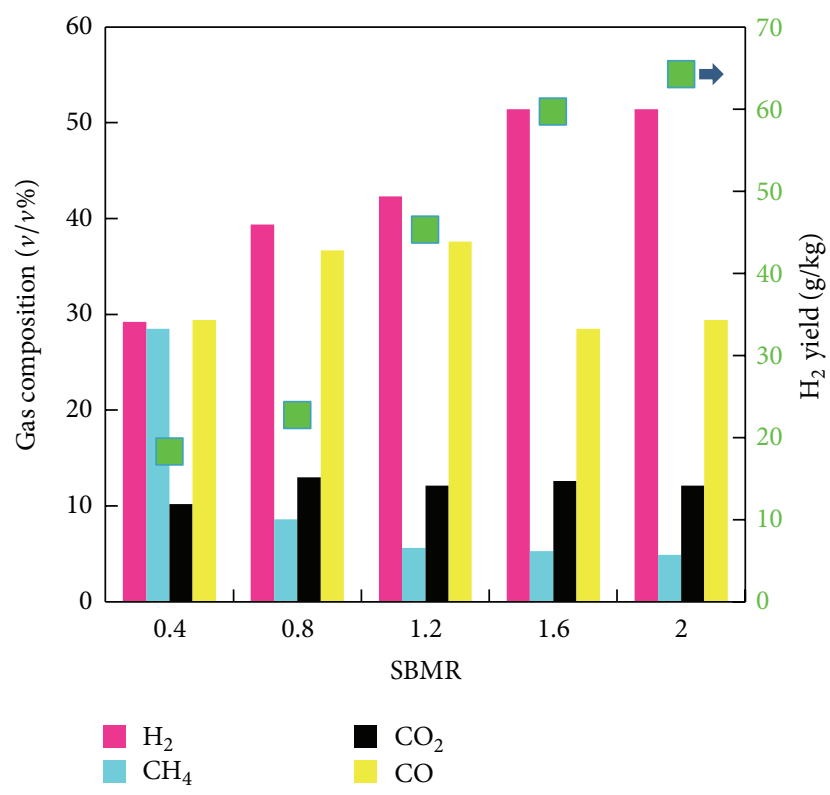

FIGURE 3: Influence of $\mathrm{SBMR}$ on $\mathrm{H}_{2}$-rich gas production.

temperature range; thus the $(\mathrm{R} 3)$ and $(\mathrm{R} 4)$ reactions have a more prevailing role.

Higher temperature contributes to higher $\mathrm{H}_{2}$ content and yield. It seems to indicate that the temperature should be kept at the highest possible value. However, we should keep in mind that higher temperature would result in other problems, such as higher operational costs and high temperature agglomeration. Therefore, proper high temperature should be considered for cogasification of coal and biomass in fluidized bed reactor.

3.2. Influences of SBMR. Figure 3 presents the influences of SBMR on $\mathrm{H}_{2}$-rich gas production at BCMR of 4 and 950$1000^{\circ} \mathrm{C}$. With the increase of SBMR from 0.4 to 2 , the $\mathrm{H}_{2}$ content and yield in the product gas increased from $29.2 \%$ and $18.25 \mathrm{~g} / \mathrm{kg}$ to $51.4 \%$ and $64.25 \mathrm{~g} / \mathrm{kg}$, respectively. Contrary to the results obtained here, Li et al. [26] found a decrease in $\mathrm{H}_{2}$ yield when SBMR increased from 0.2 to 1 . They contributed their observation to the decreased temperature resulting from heat absorbing by the excess water in their fluidized bed reactor [4]. However, for each test in this study, the temperature inside the fluidized bed reactor kept constant by taking advantage of the coal combustion, ensuring the influences of SBMR on $\mathrm{H}_{2}$-rich gas production avoiding the interference of varied temperature. The water gas reaction (R3) and all steam reforming reactions are strengthened with an increase of SBMR, which resulted in increase in $\mathrm{H}_{2}$ yield.

In regard to the gas composition, with SBMR varying from 0.4 to $2, \mathrm{H}_{2}$ content increased from $29.2 \%$ to $51.4 \%$, $\mathrm{CH}_{4}$ decreased from $28.5 \%$ to $4.9 \%$, while $\mathrm{CO}_{2}$ varied little. In particular, the variation of $\mathrm{CO}$ content did not show a monotonic trend. Molar fraction of $\mathrm{CO}$ rose as SBMR increased from 0 to 1.2 but declined as SBMR went up. Thus, maximum carbon monoxide content reached $37.6 \%$ as SBMR is 1.2. This result is related to the fact that the contents of the

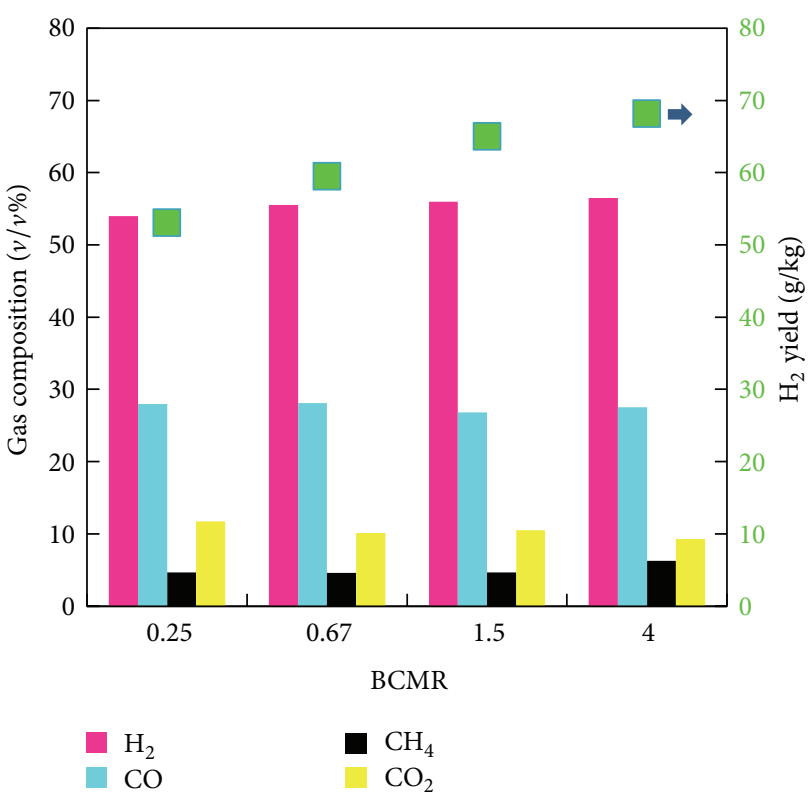

FIGURE 4: Influence of BCMR on $\mathrm{H}_{2}$-rich gas production.

$\mathrm{H}_{2}$, $\mathrm{CO}$, and $\mathrm{CO}_{2}$ were linked together by the equilibrium of the (R5) reaction in the current test conditions.

With regard to the changing trend of gas components with the varied SBMR in coal and biomass cogasification, some researchers reported different phenomena [27, 28]. The difference possibly came from the different reactor, raw materials, operating conditions, and gasifying agents used.

3.3. Influences of BCMR. Figure 4 gives the influences of BCMR on $\mathrm{H}_{2}$-rich gas production. It is found that the $\mathrm{H}_{2}$ content and yield in the product gas increased from $54 \%$ and $53.04 \mathrm{~g} / \mathrm{kg}$ at 0.25 to $56.5 \%$ and $68.13 \mathrm{~g} / \mathrm{kg}$ at 4 , respectively. Maximum $\mathrm{H}_{2}$ content reached $56.5 \%$ as BCMR is 4 . The result indicates that the total amount of the residual char after the combustion stage together with the biomass char makes water gas reaction dominate the gasification stage, which generates the highest amount of $\mathrm{H}_{2}$ when $\mathrm{BCMR}=4$. The other gas species like carbon monoxide (28\%-27.5\%), carbon dioxide $(4.7 \%-6.3 \%)$, and carbon dioxide $(11.7 \%-9.3 \%)$ are independent of the BCMR.

\section{Sensitivity Analysis}

Three operation parameters mentioned in Sections 3.1, 3.2, and 3.3 have different degree influences on hydrogen production. The hydrogen production efficiency $\left(\eta_{\mathrm{H}_{2}}\right)$ defined as (1) is used to characterize the quality of hydrogen production. The relative linear sensibility coefficient defined as (2) is used to evaluate the influences of these operating parameters on $\mathrm{H}_{2}$ production process [29]:

$$
\eta_{\mathrm{H}_{2}}=\frac{m_{\mathrm{H}_{2}} \cdot \mathrm{LHV}_{\mathrm{H}_{2}}}{m_{F} \cdot \mathrm{LHV}_{F}}
$$




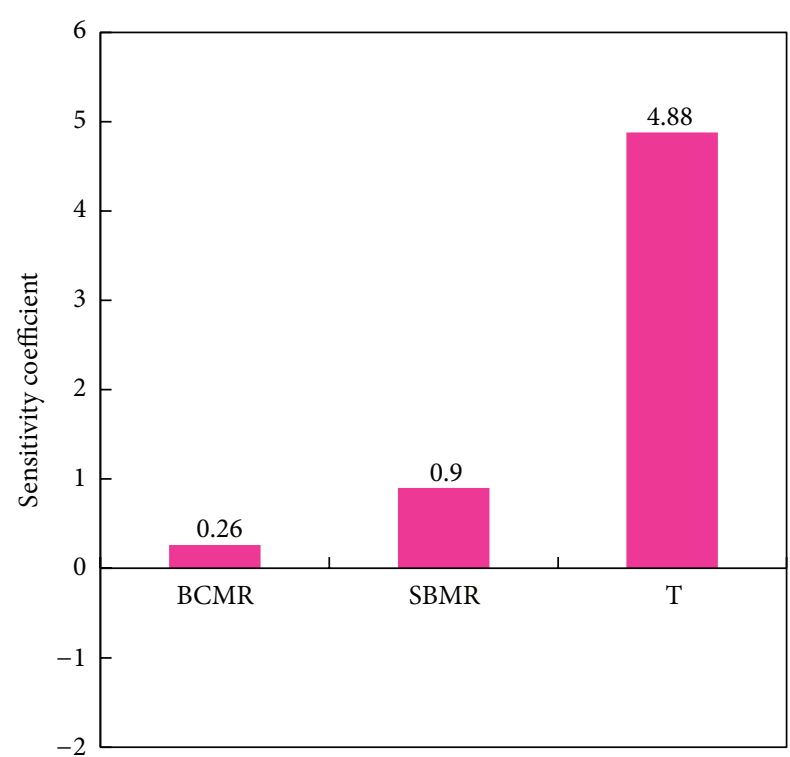

FIGURE 5: Relative linear sensitivity coefficients of $\mathrm{H}_{2}$ production efficiency towards the operation parameters.

where $m_{F}$ and $m_{\mathrm{H}_{2}}$ represent the mass of fuel and $\mathrm{H}_{2}$, respectively. $\mathrm{LHV}_{\mathrm{F}}$ and $\mathrm{LHV}_{\mathrm{H}_{2}}$ are the lowest heating values of fuel and $\mathrm{H}_{2}$, respectively,

$$
\omega_{\mathrm{i}}=\frac{\Delta \eta_{\mathrm{H}_{2}} / \eta_{\mathrm{H}_{2}}}{\Delta X_{i} / X_{i}}
$$

where $X_{i}$ is the operating parameter of number $i$.

The relative linear sensitivity coefficients of $\mathrm{H}_{2}$ production efficiency to the operation parameters such as T, SBMR, and BCMR were calculated which are given in Figure 5. As presented in Figure 5, the order of the influence of the operation parameters on $\mathrm{H}_{2}$ production efficiency is $\mathrm{T}>$ SBMR > BCMR. It is found that the sensitivity coefficients of T, SBMR, and BCMR are positive.

Consequently, the control of hydrogen production process should start from controlling T. Moreover, the increase of SBMR is helpful for the $\mathrm{H}_{2}$ production.

\section{Conclusions}

The aim of this work was to investigate the influences of $\mathrm{T}$, SBMR, and BCMR on $\mathrm{H}_{2}$-rich gas production by cogasification of coal and biomass in an intermittent fluidized bed. Additionally, a sensitivity study was employed in order to provide a comparable measure of the influence of $\mathrm{T}$, SBMR, and BCMR on $\mathrm{H}_{2}$ production efficiency. The remarkable conclusions are ordered as follows.

(i) This technology exhibits the characteristics of stability and reliability in the industrialization process. Over the ranges examined in this study, the increases of $\mathrm{T}$, SBMR, and BCMR were all favorable for promoting the $\mathrm{H}_{2}$ production. (ii) The $\mathrm{H}_{2}$ and the $\mathrm{CO}$ contents increase with increasing temperature, whilst the contents of $\mathrm{CO}_{2}$ and $\mathrm{CH}_{4}$ decrease correspondingly.

(iii) With increasing SBMR, the $\mathrm{H}_{2}$ content and yield in the product gas increase. $\mathrm{CH}_{4}$ in the gas decreases with SBMR, whilst $\mathrm{CO}$ increases first and then decreases correspondingly.

(iv) The BCMR has a weak influence on composition of gas produced, but the yield and content of hydrogen increase with increasing BCMR, reaching a peak at the BCMR of 4.

(v) The order of the influence of the operation parameters on $\mathrm{H}_{2}$ production efficiency is $\mathrm{T}>\mathrm{SBMR}>\mathrm{BCMR}$.

\section{Acknowledgments}

This work was financed by the Agricultural Achievement Transforming Capital Projects of the Ministry of Science and Technology (Project no. 2008GB2C100099), Power Machinery, Clean Energy, and Application of Key Laboratory Projects of Jiangsu Province (Project no. QK09005), Science and Technology Project of Suzhou Province (no. 040105), and Science and Technology Support Project of Jiangsu Province (Project no. BE2008051).

\section{References}

[1] M. K. Cohce, M. A. Rosen, and I. Dincer, "Efficiency evaluation of a biomass gasification-based hydrogen production," International Journal of Hydrogen Energy, vol. 36, no. 17, pp. 1138811398, 2011.

[2] G. Ruoppolo, P. Ammendola, R. Chirone, and F. Miccio, " $\mathrm{H}_{2}$ rich syngas production by fluidized bed gasification of biomass and plastic fuel," Waste Management, vol. 32, no. 4, pp. 724-732, 2012.

[3] Z. G. Tang, P. Y. Ma, J. P. Cheng, Y. L. Li, and Q. Z. Lin, "A novel biomass gasifier for producing tar-free and hydrogen-rich syngas," Advanced Materials Research, vol. 105-106, no. 1, pp. 709-712, 2010.

[4] L. Han, Q. Wang, Y. Yang, C. Yu, M. Fang, and Z. Luo, "Hydrogen production via $\mathrm{CaO}$ sorption enhanced anaerobic gasification of sawdust in a bubbling fluidized bed," International Journal of Hydrogen Energy, vol. 36, no. 8, pp. 4820-4829, 2011.

[5] H. Guoxin and H. Hao, "Hydrogen rich fuel gas production by gasification of wet biomass using a $\mathrm{CO}_{2}$ sorbent," Biomass and Bioenergy, vol. 33, no. 5, pp. 899-906, 2009.

[6] N. Gao, A. Li, C. Quan, and F. Gao, "Hydrogen-rich gas production from biomass steam gasification in an updraft fixedbed gasifier combined with a porous ceramic reformer," International Journal of Hydrogen Energy, vol. 33, no. 20, pp. 54305438, 2008.

[7] J. H. Kuo, C. L. Lin, and M. Y. Wey, "Effect of agglomeration/ defluidization on hydrogen generation during fluidized bed air gasification of modified biomass," International Journal of Hydrogen Energy, vol. 37, pp. 1409-1417, 2012.

[8] A. Bhattacharya, A. Bhattacharya, and A. Datta, "Modeling of hydrogen production process from biomass using oxygen blown gasification," International Journal of Hydrogen Energy, vol. 37, pp. 18782-18790, 2012. 
[9] V. Skoulou, G. Koufodimos, Z. Samaras, and A. Zabaniotou, "Low temperature gasification of olive kernels in a $5-\mathrm{kW}$ fluidized bed reactor for $\mathrm{H}_{2}$-rich producer gas," International Journal of Hydrogen Energy, vol. 33, no. 22, pp. 6515-6524, 2008.

[10] S. I. Ngo, T. D. B. Nguyen, Y. Lim et al., "Performance evaluation for dual circulating fluidized-bed steam gasifier of biomass using quasi-equilibrium three-stage gasification model," Applied Energy, vol. 88, no. 12, pp. 5208-5220, 2011.

[11] P. Weerachanchai, M. Horio, and C. Tangsathitkulchai, "Effects of gasifying conditions and bed materials on fluidized bed steam gasification of wood biomass," Bioresource Technology, vol. 100, no. 3, pp. 1419-1427, 2009.

[12] E. D. Gordillo and A. Belghit, "A bubbling fluidized bed solar reactor model of biomass char high temperature steam-only gasification," Fuel Processing Technology, vol. 92, no. 3, pp. 314321, 2011.

[13] A. Kumar, K. Eskridge, D. D. Jones, and M. A. Hanna, "Steamair fluidized bed gasification of distillers grains: effects of steam to biomass ratio, equivalence ratio and gasification temperature," Bioresource Technology, vol. 100, no. 6, pp. 2062-2068, 2009.

[14] P. M. Lv, Z. H. Xiong, J. Chang, C. Z. Wu, Y. Chen, and J. X. Zhu, "An experimental study on biomass air-steam gasification in a fluidized bed," Bioresource Technology, vol. 95, no. 1, pp. 95-101, 2004.

[15] L. Wei, S. Xu, L. Zhang, C. Liu, H. Zhu, and S. Liu, "Steam gasification of biomass for hydrogen-rich gas in a free-fall reactor," International Journal of Hydrogen Energy, vol. 32, no. 1, pp. 24-31, 2007.

[16] Y. Wang, F. Larachi, and S. Roy, "Simulating the dynamics of gas-solid flows in a multichannel microcirculating fluidized bed," Industrial and Engineering Chemistry Research, vol. 48, no. 17, pp. 7928-7937, 2009.

[17] O. Levenspiel, "What will come after petroleum?" Industrial and Engineering Chemistry Research, vol. 44, no. 14, pp. 5073-5078, 2005.

[18] C. Pfeifer, R. Rauch, and H. Hofbauer, "In-bed catalytic tar reduction in a dual fluidized bed biomass steam gasifier," Industrial and Engineering Chemistry Research, vol. 43, no. 7, pp. 1634-1640, 2004.

[19] L. Wei, S. Xu, J. Liu, C. Lu, S. Liu, and C. Liu, "A novel process of biomass gasification for hydrogen-rich gas with solid heat carrier: preliminary experimental results," Energy and Fuels, vol. 20, no. 5, pp. 2266-2273, 2006.

[20] L. Wei, S. Xu, J. Liu, C. Liu, and S. Liu, "Hydrogen production in steam gasification of biomass with $\mathrm{CaO}$ as a $\mathrm{CO}_{2}$ absorbent," Energy and Fuels, vol. 22, no. 3, pp. 1997-2004, 2008.

[21] T. Murakami, G. Xu, T. Suda, Y. Matsuzawa, H. Tani, and T. Fujimori, "Some process fundamentals of biomass gasification in dual fluidized bed," Fuel, vol. 86, no. 1-2, pp. 244-255, 2007.

[22] L. Q. Wang, Y. H. Dun, X. N. Xiang, Z. J. Jiao, and T. Q. Zhang, "Thermodynamics research on hydrogen production from biomass and coal co-gasification with catalyst," International Journal of Hydrogen Energy, vol. 36, no. 18, pp. 11676-11683, 2011.

[23] F. Yan, S. Luo, Z. Hu, B. Xiao, and G. Cheng, "Hydrogen-rich gas production by steam gasification of char from biomass fast pyrolysis in a fixed-bed reactor: influence of temperature and steam on hydrogen yield and syngas composition," Bioresource Technology, vol. 101, no. 14, pp. 5633-5637, 2010.

[24] L. Q. Wang and Z. S. Chen, "Gas generation by co-gasification of biomass and coal in an autothermal fluidized bed gasifier," Applied Thermal Engineering, vol. 59, pp. 278-282, 2013.
[25] I. Iliuta, A. Leclerc, and F. Larachi, "Allothermal steam gasification of biomass in cyclic multi-compartment bubbling fluidized-bed gasifier/combustor-new reactor concept," Bioresource Technology, vol. 101, no. 9, pp. 3194-3208, 2010.

[26] K. Li, R. Zhang, and J. Bi, "Experimental study on hydrogenrich gas production by co-gasification of coal and biomass in a fluidized bed," Journal of Fuel Chemistry and Technology, vol. 38, no. 6, pp. 660-665, 2010.

[27] F. Pinto, C. Franco, R. N. André, M. Miranda, I. Gulyurtlu, and I. Cabrita, "Co-gasification study of biomass mixed with plastic wastes," Fuel, vol. 81, no. 3, pp. 291-297, 2002.

[28] F. Pinto, C. Franco, R. N. André et al., "Effect of experimental conditions on co-gasification of coal, biomass and plastics wastes with air/steam mixtures in a fluidized bed system," Fuel, vol. 82, no. 15-17, pp. 1967-1976, 2003.

[29] J. Guan, Q. Wang, X. Li, Z. Luo, and K. Cen, "Thermodynamic analysis of a biomass anaerobic gasification process for hydrogen production with sufficient CaO," Renewable Energy, vol. 32, no. 15, pp. 2502-2515, 2007. 


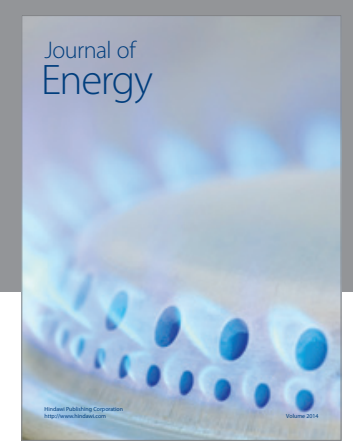

Journal of

Industrial Engineering
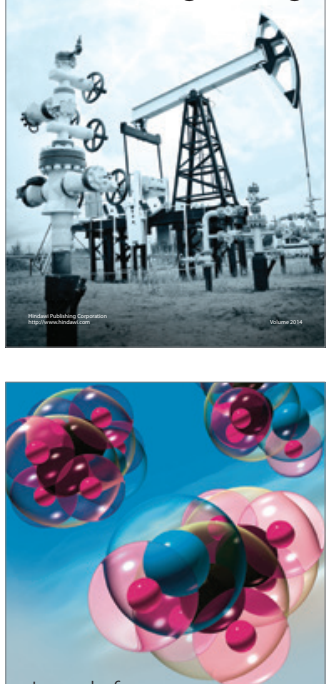

Fuels
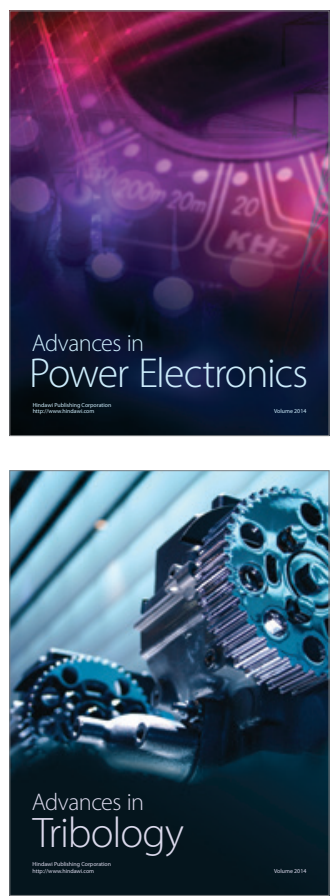

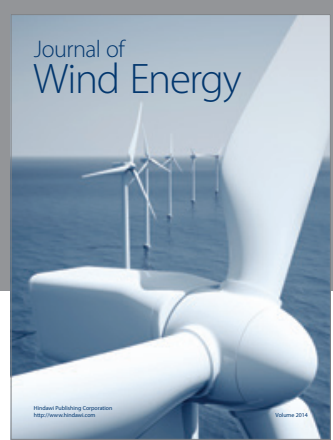

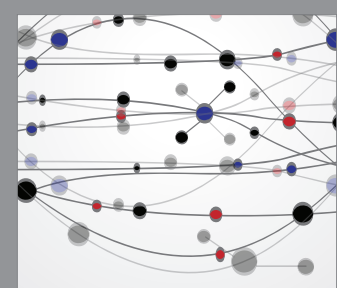

The Scientific World Journal

Submit your manuscripts at http://www.hindawi.com

Journal of

Structures
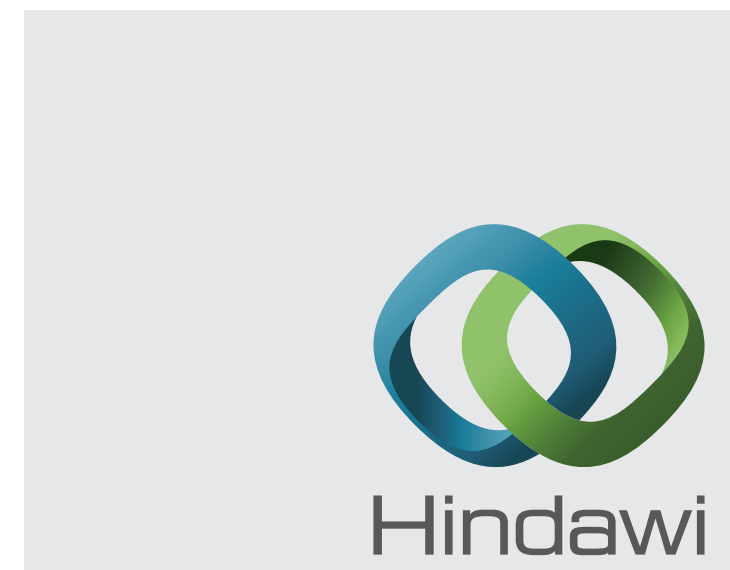

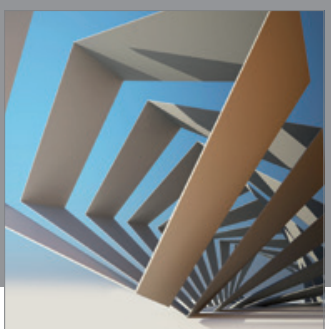

Rotating

Machinery
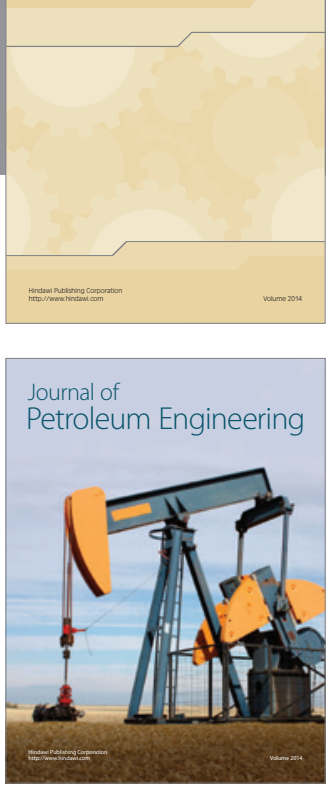

Journal of

Solar Energy
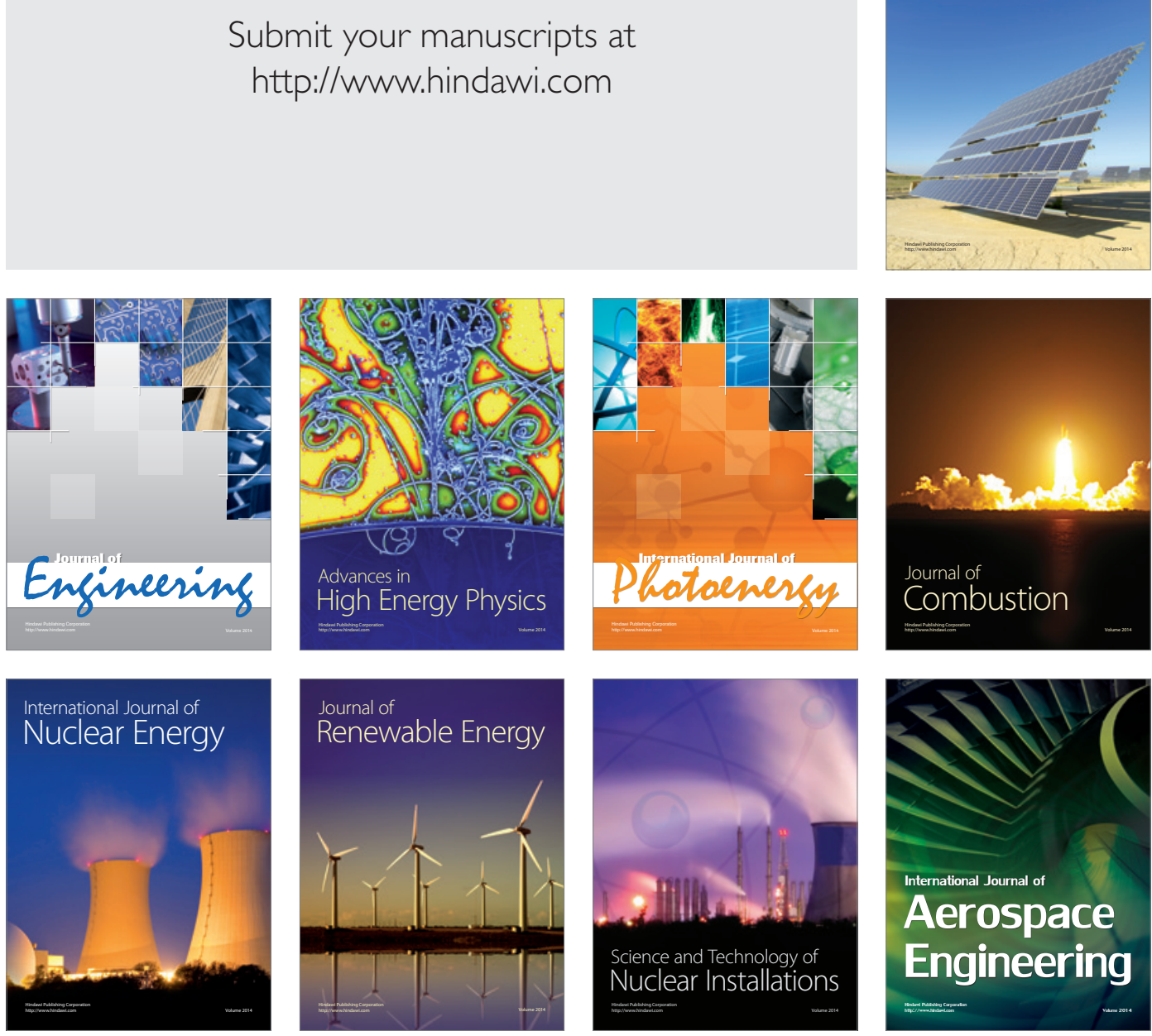